\title{
The McKee Worker-Consistometer with Constant-Speed Drives
}

\author{
Samuel A. McKee and Hobart S. White
}

\begin{abstract}
Two constant-speed drives have been developed for use with the McKee worker-consistometer for mechanically working a fluid and measuring its flow characteristics in the same series of operations. Previously, weights were used to provide various constant loads at which measurements were made of the rate of flow of the material under test. The modifications provide for measurements of the resultant forces when operating at constant rates of flow. They permit the determination of the effect of wot king at various constant rates of shear and also provide for a much greater range of loads.

Test data are given showing the effect of mechanical working upon the flow characteristics of some lubricating greases and some raw synthetic rubbers.

The results show that the apparatus provides a tool useful in the measurement of the apparent viscosity and the effect of mechanical working for non-Newtonian materials having thixotropic properties. The performance of the apparatus is adequate to cover consistencies of materials ranging from a light lubricating grease to 100 percent of raw rubber.
\end{abstract}

\section{Introduction}

The development of a worker-consistometer for investigating the effect of mechanical working on the physical properties of lubricating greases has been described in a previous publication. ${ }^{1}$ With this apparatus a grease or similar material may be worked and its flow characteristics measured in the same series of operations. It consists essentially of two coaxial steel cylinders and mating pistons with a capillary shearing element between them. By means of the closely fitting pistons the material being tested is forced repeatedly through the shearing element from one cylinder to the other. The shearing elements were made by drilling holes in steel disks $1 / 4$ in. thick, using a No. 79 drill. With the original apparatus, weights acting on the top piston provide a constant load during the downward pass when the rate of flow is being measured; an air cylinder with leather-cup piston and rod acts against the lower piston during the upward pass.

With materials such as greases and some rubber solutions, the rate of shear changes with working when a constant load is used. Recent work has been directed toward increasing the usefulness of the worker-consistometer by modifications that (1) permit operation at constant nominal rates of shear and (2) extend the range to higher viscosities. The modified instrument is suitable for studies of the rheological properties of rubber and rubber solutions, as well as greases and similar substances.

The modifications required were concerned cheifly with the driving mechanism and with the method for measuring the forces involved. Two constantspeed drives have been constructed: one is a camoperated mechanism with a load range up to 200 $\mathrm{lb}$; the other is a screw-operated drive with a capacity of $1,600 \mathrm{lb}$. The operation of each mechanism is automatic, and is such that readings of the forces may be taken at desired intervals during a run of continual working.

1 S. A. McKee and H. S. White, A worker-consistometer for lubricating greases, ASTM Bul. 153, 90 (Aug. 1948).
This paper presents details on the construction, operation, and range of the new driving mechanisms, together with examples of the application of the modified worker-consistometer to four lubricating greases and five synthetic rubbers.

\section{Apparatus}

The design of the major elements of the workerconsistometer has been retained. This has been described in the previous publication (see footnote1). Each worker unit consists of two coaxial steel cylinders and mating pistons with a capillary type shearing element between them. Relative motion between pistons and cylinders forces the material under test through the shearing element. Views of two worker units are shown in figure 1. A set of unassembled parts is on the left, and an assembled unit is on the right. Four such units are now available for use. Each is provided with 1-, 10-, and 50-hole shearing elements. These shearing elements are made by drilling holes in circular steel disks $1 / 4 \mathrm{in}$. thick, using a No. 79 drill, giving capillaries $1 / 4$ in. long and about 0.015 in. in diameter.

\section{Cam-Operated Machine}

With the cam-driven apparatus, the pistons are moved back and forth by a motor-driven camoperated mechanism, and determinations of the pressure developed in pushing the material under test through the capillaries in the shearing element are made by measuring the force required to hold the cylinders in a fixed position. Views of this apparatus are given in figures 2,3 , and 4 . The worker unit (shown in fig. 1) is enclosed in the duralumin housing, $A$, (fig. 2), which is encircled by the electric heater, $B$. A mercury-in-glass thermal regulator placed in a perforated tube is used to control the test temperature, which is measured by a thermocouple contacting the shearing element. The flanges at the ends of the housing are attached to flexure plates, which provide "free" action along the vertical axis. The weight of the housing and parts 
supported by it is counter-balanced by the weight, $C$, (fig. 4) mounted on a lever arm. This arm is provided with a pointer and scale, the zero position of which indicates when the system is in balance with no deflection in the flexure plates.

The operating yoke, $E$, (fig. 2) guided by bearings, $F$, is actuated by the cam, $H$, and moves the pistons back and forth, a distance of approximately 2 in., by means of the push rods, $K$. During the upward pass, the force transmitted to the cylinder assembly by the action of the piston in pushing the material under test through the shearing element is measured by the weighing scale, which is connected to housing $A$ by rods acting through an 8 to 1 lever arm. The arrangement is such that the load range is from 0 to $120 \mathrm{lb}$ with weight $D$ (fig. 4) in place and from 80 to $200 \mathrm{lb}$ when $D$ is removed. A turnbuckle on the rod from the scale permits adjustment to compensate for the scale travel, so as to keep housing $A$ in its zero (balanced) position when reading the scale. Movement of the housing is limited by adjustable stops, and on the downward pass the force is taken by the lower stop. A counter actuated by each downward stroke of the yoke records the revolutions of the cam.

The pointer, $L$, mounted on yoke $E$ moves along a steel measuring scale and is used for measuring the speed of the pistons.

Cam $H$ is mounted on a shaft supported by two ball bearings. The shaft is connected to a positiveaction variable-speed transmission. A 36-rpm gear motor supplies the power to the transmission through a four-step combination of $V$-pulleys and a 30 to 1 reduction gear. The gear motor is mounted on a hinged base so that the V-belt can be easily shifted to a different set of grooves. This driving mechanism in conjunction with the use of the 1-, 10-, or 50-hole disks provides a continuous range of nominal rates of shear from 200 to 100,000 reciprocal seconds, the latter value being limited, not by the drive, but by the length of time required for making an accurate load observation. The range of rates of shear covered with any given material under test is, of course, also limited by the load range of 1 to $200 \mathrm{lb}$. For a broad range of rate of shear this load range corresponds to a viscosity range from 1 to 100 poises; and for a relatively low rate of shear of 200 reciprocal seconds, the viscosity range is from 20 to 4,000 poises.

\section{Screw-Operated Machine}

With the screw-operated apparatus the cylinders of the worker unit are moved back and forth, and the force measured is that required to hold the pistons in a fixed position. This apparatus is shown in figures 5, 6, and 7 . The worker unit is enclosed in a steel housing with a thermo couple and temperature control as described for the cam-driven apparatus. The housing flanges are attached to a steel operating-yoke, $M$ (fig. 5), which is mounted in three sleeve bearings attached to a heavy steel plate mounted in a vertical position. This mounting is such that the yoke may be moved up and down, but rotation is prevented.

Fastened to the lower end of the yoke is a bronze screw, $N$, which engages a steel nut, $P$, mounted on two ball bearings housed in a steel box, $R$. One of the interchangeable gear trains that connect the nut to a reversible gear motor is shown in figure 5 . Adjustable screws on the yoke contact push buttons that operate magnetic switches that automatically reverse the motor at the end of each upward and downward stroke of the voke. These screws and push buttons are adjusted for a stroke of about 2 in. A counter is actuated at the end of each downstroke of the yoke.

During the reciprocating motion of the cylinders the pistons are restrained from moving by loading pins, $S$, acting against calibrated steel springs, $T$. A dial indicator measures the deflection of the cantilever arm of the spring and hence the force necessary to push the material under test through the capillaries in the shearing element. Five pairs of springs of different capacity cover the range of loads up to $1,600 \mathrm{lbs}$. The gear trains provide a number of rates of shear ranging from less than 1 to 100,000 reciprocal seconds. The range of viscosity is eight times greater than that of the cam mechanism for its range of rate of shear (200 to $\left.100,000 \mathrm{sec}^{-1}\right)$. With the screw-operated apparatus the range of viscosity determinations is extended to 600,000 poises at 10 recriprocal seconds or $6,000,000$ poises at 1 reciprocal second.

\section{Accessories}

In testing samples that cannot be readily poured, the filling apparatus shown at the left in figure 8 was used. It consists of a split cylinder, piston clamping ring, and positioning ring. After the two halves of the cylinder are filled with the sample, they are assembled and positioned against the end of a worker cylinder, and by means of the filling piston the sample is transferred to the worker cylinder. When the worker is assembled the worker pistons are coated with the test sample to insure that the clearance space is filled, and care is taken to prevent trapping air with the sample.

For the removal of air from spongy materials such as rubber, steel tubes with loose-fitting steel pistons are used. After small pieces of the sample are forced into the steel tube, a piston is started into each end, and a load of a few hundred pounds is placed on the pistons for several hours. The plug-shaped sample thus formed is pressed out of the tube, assembled in the split cylinder, and transferred to the worker. When using rubber samples, a piece of the rubber moistened with benzol is rubbed against the worker pistons until a coating is formed, and the coated pistons are pushed through the cylinders a few times until both are coated. The benzol is then allowed to evaporate before assembly.

In cases where it is desirable to store a sample intact for future test, a special cylinder is used. A storage cylinder with its piston, cap, positioning ring, 
and push rods is shown on the right in figure 8. A storage-cylinder assembly containing a stored sample is shown also. The push rod having two steps is used to push the worker piston when transferring a sample to a storage cylinder, and the push rod with one step is used to push on the storage piston when transferring the sample back to the worker.

\section{Calibration}

The shearing elements were calibrated in their respective cylinder assemblies with oils of known viscosity in the manner described in the previous paper (see footnote 1). As these oils are Newtonian fluids, the flow may be represented by the equation,

$$
\eta=\frac{S}{R}=\frac{\frac{r P}{2 L}}{\frac{4 V / t}{\pi r^{3}}}=\frac{K_{S} W}{K_{R} V / t},
$$

where

$\eta=$ absolute viscosity, poises

$S=$ shearing stress at the wall of the capillary, dynes $/ \mathrm{cm}^{2}$

$R=$ rate of shear at wall, $\mathrm{sec}^{-1}$

$P=$ pressure drop across the capillary, dynes/ $\mathrm{cm}^{2}$

$L=$ length of capillary, em

$r=$ radius of capillary, $\mathrm{cm}$

$V / t=$ volume rate of flow per capillary, $\mathrm{cm}^{3} / \mathrm{sec}$

$W=$ load on piston, $\mathrm{lb}$

$K_{S}=$ shearing stress constant

$K_{R}=$ rate of shear constant.

The piston friction for each assembly was also determined by operating with an oil of known viscosity with the shearing element removed from the unit. The values obtained were used as a correction to $K_{S}$, the shearing stress constant and also for determining the average diametral clearance between the cylinders and mating pistons.

The values obtained in the calibrations of the respective worker-units and shearing elements are given in table 1.

TABLE 1. Calibration constants of worker units and shearing elements

\begin{tabular}{|c|c|c|c|c|c|c|}
\hline $\begin{array}{c}\text { Worker } \\
\text { unit }\end{array}$ & $\begin{array}{l}\text { Average } \\
\text { diametral } \\
\text { clearance }\end{array}$ & Disk & $\begin{array}{c}\text { Number } \\
\text { of } \\
\text { holes }\end{array}$ & $\begin{array}{c}\text { Average } \\
\text { diameter } \\
\text { of holes }\end{array}$ & $K_{\mathrm{R}}$ & $K_{\mathrm{S}}$ \\
\hline $\begin{array}{l}3 \\
4\end{array}$ & $\begin{array}{c}\text { in. } \\
0.00015 \\
.00036 \\
.00081\end{array}$ & $\begin{array}{l}31 \\
41 \\
42 \\
43 \\
51 \\
52 \\
53\end{array}$ & $\begin{array}{r}1 \\
1 \\
10 \\
50 \\
1 \\
10 \\
50\end{array}$ & $\begin{array}{c}i n . \\
0.01503 \\
.01506 \\
.01469 \\
.01460 \\
.01487 \\
.01453 \\
.01477\end{array}$ & $\begin{array}{l}183,000 \\
182,000 \\
196,000 \\
200,000 \\
189,000 \\
202,000 \\
193,000\end{array}$ & $\begin{array}{l}5,055 \\
4,980 \\
4,710 \\
4,135 \\
4,930 \\
4,750 \\
4,530\end{array}$ \\
\hline
\end{tabular}

For convenience in measuring a very wide range of consistencies, the different units have different clearances between pistons and cylinders. In general, unit 3 with disk 31 is used with low-viscosity samples, as the small clearance minimizes leakage, and the higher piston friction is still a relatively small correction when using the 1-hole disk. Unit 5 with disk 53 is used for the very high viscosity samples. When a 50-hole disk is used, the larger clearance of unit 5 is desirable to reduce the piston-friction correction. Unit 4, which is a compromise between leakage and piston friction, is usually used for samples of intermediate consistency. With this unit the piston-friction corrections are $0.4,3.4$, and 14.7 percent for disks 41, 42, and 43, respectively.

Some indication of the accuracy obtainable with the apparatus is given in figure 9, where viscosity data are plotted against rate of shear. Sample N-15 is a Newtonian oil, and the horizontal lines represent the viscosities at the temperatures indicated obtained with a modified Ostwald viscometer, whereas the points represent the viscosities obtained at the same temperatures, using worker-unit 4 . When using this unit for viscosities below 1 poise, a greater spread of the data would be expected because of the low loads involved.

Data are also given in figure 9 for a non-Newtonian solution of GR-I rubber in a light mineral oil obtained with worker-unit 4 with all three disks. In order to cover the same range of rates of shear with disks 43 (50 holes) and 41 (1 hole), some runs with the latter were made by applying small dead-weight loads to the upper piston. These are indicated by the crosses. The good general agreement of the data obtained with all three disks is of particular interest. The apparatus was calibrated with Newtonian fluids, and as the rates of shear at capillary and piston walls are not the same, some error would be expected in applying piston-friction corrections when working with a non-Newtonian material. However, the data indicate that in this particular case the error is quite small.

\section{Test Results}

The test data are given in this paper primarily to illustrate the application of the apparatus to certain investigations. They are not of sufficient scope to provide specific relations between the rheological properties of the materials and other properties or factors involved.

In the previous publication (see footnote 1) results were given on the effect of mechanical working on the flow characteristics of various lubricating greases when operating in the worker-consistometer at various constant loads. Under such conditions the rates of shear to which the grease was subjected varied throughout the test. Flow measurements were made with two of these greases, grease A (lithium soap) and grease D (sodium soap), when operating at $100^{\circ} \mathrm{F}$ at various constant rates of shear. The results are given in figures 10 and 11 , where the apparent viscosity (plotted on a log scale for convenience) is plotted against the number of passes through the shearing element. In each test at a given rate of shear, flow measurements were taken at intervals during a period of mechanical working of 200 passes, after which the sample was 
transferred to a storage cylinder. After 4 weeks of storage at room temperature, flow measurements were made with each sample during a working period of 26 passes. 'They were then subjected to an additional storage period of 35 weeks and another 26pass working period.

With both of these greases the effect of mechanical working in lowering the viscosity was quite marked during the first 200 passes. With each grease this change in viscosity is roughly proportional at all rates of shear over the range covered. The ratio of the viscosity at the 200th pass to the viscosity at the first pass was approximately 0.6 for grease $\mathrm{A}$ and 0.5 for grease D.

The data taken at the first pass after a storage period provides an indication of the so-called healing process. In general there was a measurable increase in viscosity after storage. Apparently grease A had become relatively stable (with respect to mechanical working) after the first working period, as subsequent working after storage periods did not lower the viscosity much below that at the 200th pass, whereas with grease $\mathrm{D}$ there was a definite lowering in viscosity beyond the 200 pass.

Figure 12 shows the relationship between apparent viscosity and nominal rate of shear for both greases at various degrees of working. The points for 1,10 , and 100 passes were obtained from the curves in figures 10 and 11. Over the range covered with a given grease and a given pass, a linear relationship was obtained on the logarithmic plot.

Flow tests were made also on four other greases: grease $\mathrm{F}$ (soda-lime soap) and greases $\mathrm{G}, \mathrm{H}$, and $\mathrm{J}$ (soda soap). At a rate of shear of 18,100 reciprocal seconds and test temperatures of $100^{\circ}$ and $245^{\circ} \mathrm{F}$, apparent viscosities were determined at intervals during 226 passes with a 4 -week storage period after the 200 th pass. The data obtained are given in figures 13 and 14, where the viscosity (on a logarithmic scale) is plotted against the number of passes. Figure 13 indicates that with grease $\mathrm{G}$ the increase in temperature from $100^{\circ}$ to $245^{\circ} \mathrm{F}$ caused a very marked reduction in the viscosity of the grease in both the unworked and worked condition. On the other hand, when grease $\mathrm{F}$ was worked at the higher temperature its viscosity increased to such an extent that at the 200th pass there was not much difference in viscosity at the two test temperatures. A similar trend of lesser degree is shown also by grease $\mathrm{H}$ in figure 14 .

The screw-operated mechanism was designed primarily for an investigation of the rheological properties of various synthetic rubbers and solutions containing high percentages of rubber. ${ }^{2}$ 'The range of operation of the apparatus is such that it is capable of measuring viscosities as high as several million poises at low rates of shear and as low as a poise at high rates of shear. Accordingly, it may be used for determining the viscosities of rubber solutions ranging from 10 to 100 percent of rubber.

\footnotetext{
${ }^{2}$ This investigation is being conducted in cooperation with the Office of Rubber Reserve, Reconstruction Finance Corp.
}

Data showing the effect of working on the viscosity of five GR-S rubbers are given in figure 15. Samples $\mathrm{X}-418$ and $\mathrm{X}-478$ are rubbers in commercial production, and 1,2 , and 3 are special experimental samples. In these tests, 100 passes were made with each sample at a rate of shear of 99 reciprocal seconds and at a temperature of $212^{\circ} \mathrm{F}$. In each case there was an increase in viscosity during the first few passes, after which the behavior was different for different samples. It is of interest that whereas samples 2 and 3 have the same Mooney numbers, ${ }^{3}$ their apparent viscosities differed considerably under the present test conditions. The deviations of the points from the curves for samples 1 and X-418 at 30 and 50 passes, respectively, were caused by apparent thixotropic effects after periods of standing in the apparatus.

Data showing the effects of rate of shear on the apparent viscosities at $212^{\circ} \mathrm{F}$ of $\mathrm{X}-418$ and $\mathrm{X}-478$ rubbers are given in figure 16 . The data for each curve shown were obtained with a given sample, hence the individual values obtained are affected to some extent by the work done previously on the sample. These curves deviate slightly from the linear when plotted on a log-log scale.

Curves showing the change in viscosity with temperature for these two rubbers are shown in figure 17 . These tests were run at a rate of shear of 24.3 reciprocal seconds on samples that had been previously worked over 100 passes. Over the range covered, the relation between $\log$ viscosity and temperature for the $\mathrm{X}-478$ rubber was found to be approximately linear, while with the $\mathrm{X}-418$ rubber the increase in $\log$ viscosity with decrease in temperature was proportionally greater at the lower temperatures.

\section{Summary}

One of the chief advantages of the worker-consistometer is that samples of various materials may be worked and their flow characteristics measured in the same series of operations. The multihole disks give flexibility in covering wide ranges of rates of shear and consistency.

The cam-operated mechanism is suitable for making flow measurements at various constant speeds, which give a range of 200 to 100,000 reciprocal seconds for the nominal rate of shear. The load range is from 1 to $200 \mathrm{lbs}$. For a broad range of rate of shear, this load range corresponds to a viscosity range from 1 to 100 poises; and for a relatively low rate of shear of 200 reciprocal seconds, the viscosity range is from 20 to 4,000 poises.

The screw-operated mechanism is provided with a number of gear trains to give constant speeds corresponding to rates of shear ranging from 1 to 100,000 reciprocal seconds. Five pairs of calibrated springs cover a range of load from 1 to $1,600 \mathrm{lbs}$, which gives a range of viscosity eight times greater than that of the cam mechanism for its range of rate of shear (200 to $\left.100,000 \mathrm{sec}^{-1}\right)$. With the screw-

\footnotetext{
${ }^{3}$ M. Mooney, A shearing-disk plastometer for unvulcanized rubber, Ind. Eng. Chem., Anal. Ed. 6, 147 (1934).
} 
operated apparatus, the range of viscosity determinations is extended to 600,000 poises at 10 reciprocal seconds or $6,000,000$ poises at 1 reciprocal second.

The test data presented indicate the usefulness of the modified worker-consistometer in the study of the effect of temperature, rate of shear, and mechanical working upon the apparent viscosity of non-
Newtonian materials having thixotropic properties. The performance of the apparatus was adequate to cover consistencies of materials ranging from a light lubricating grease up to and including 100 percent of raw rubber.

Washington, July 25, 1950.

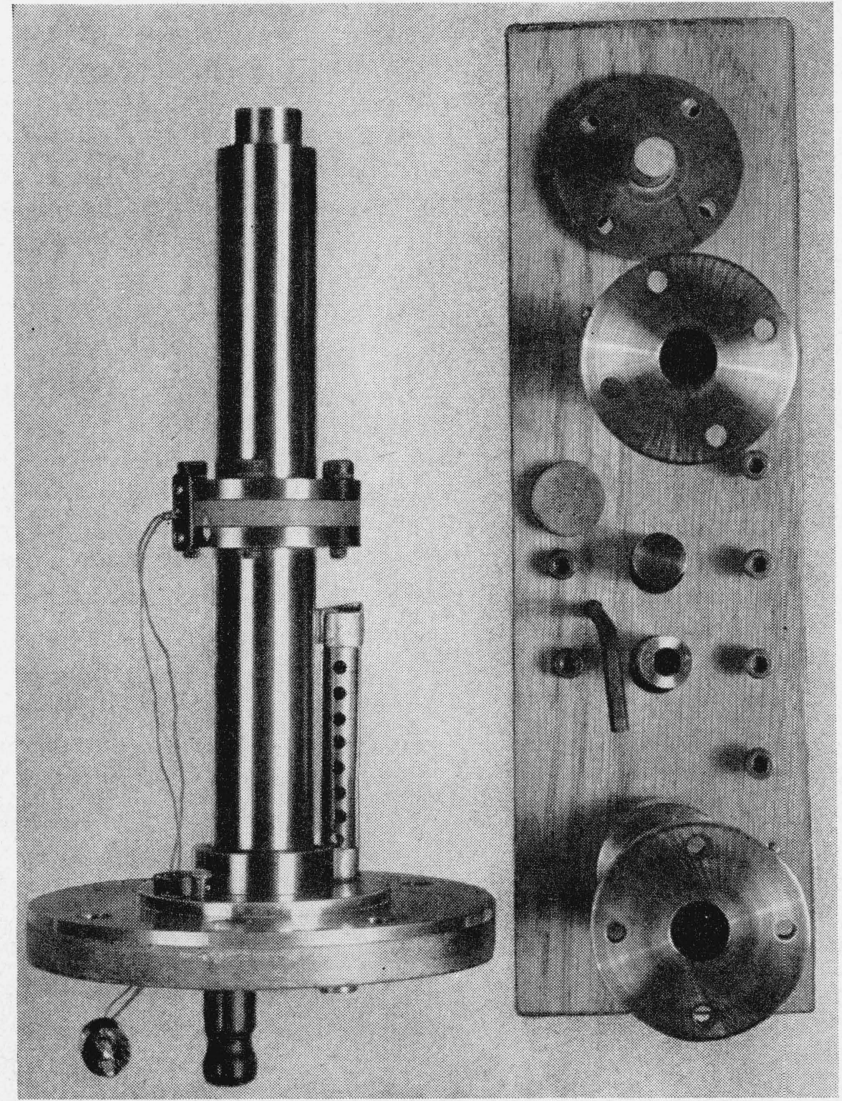

Figure 1. Major elements of worker-consistometer. 

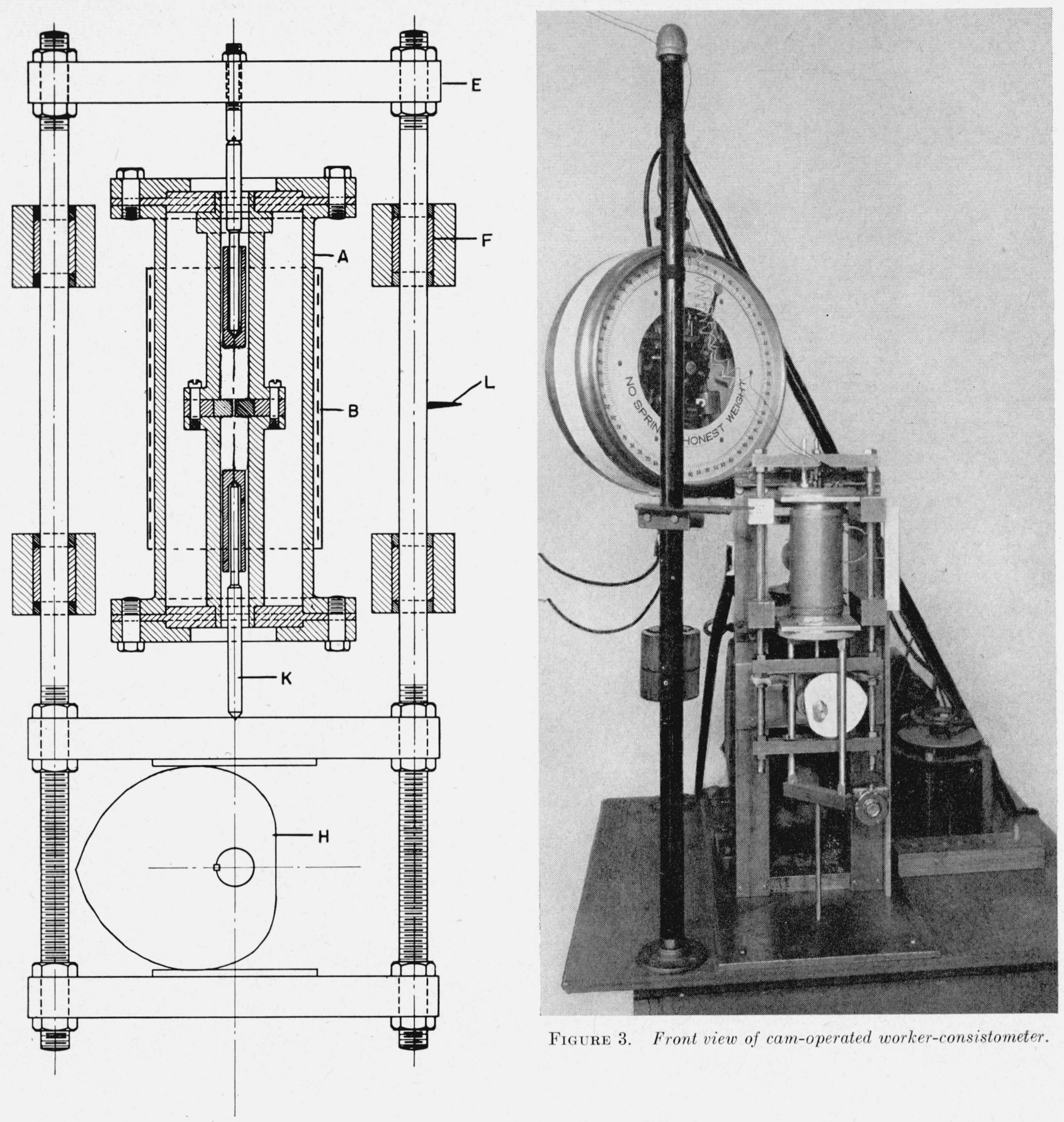

FiguRE 3. Front view of cam-operated worker-consistometer.

Figure 2. Cross section of cam-operated worker-consistometer. 


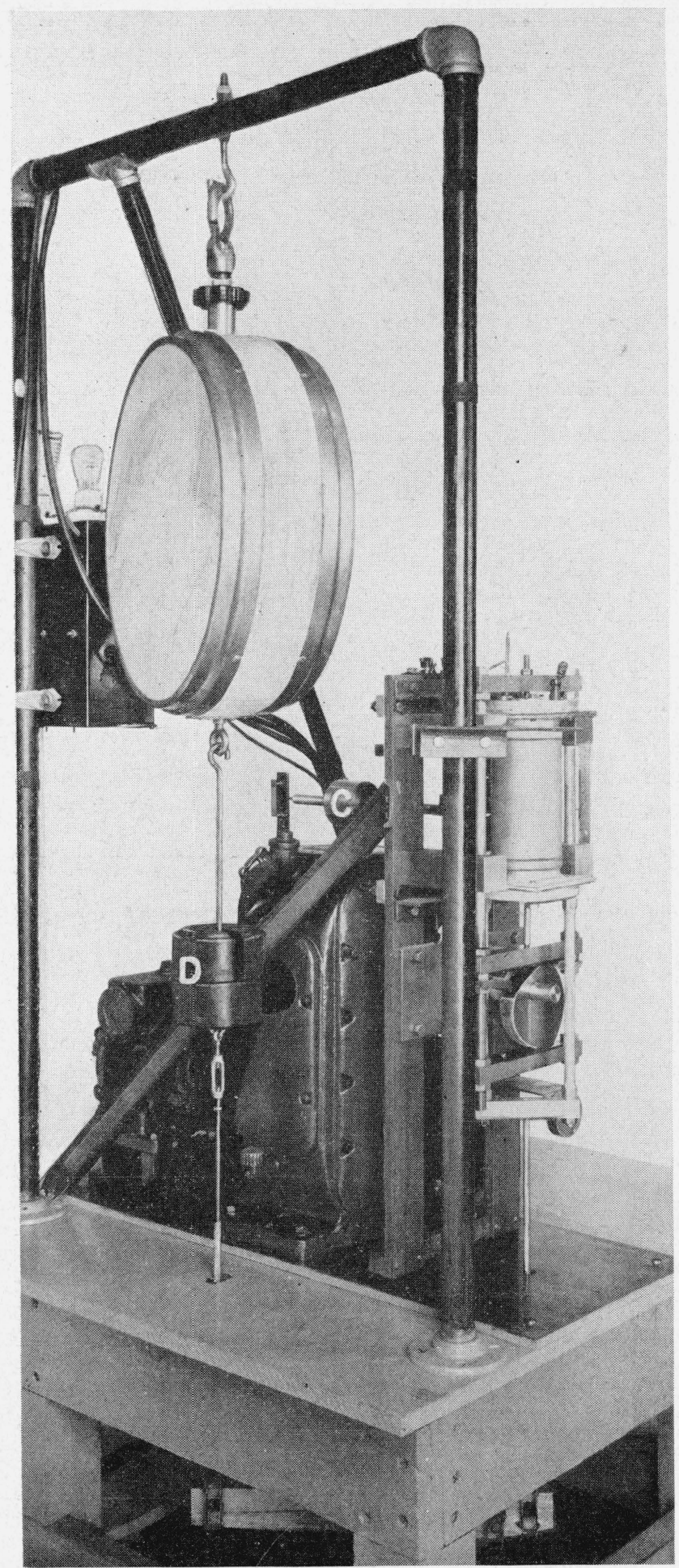

FiguRE 4. Side view of cam-operated worker-consistometer.

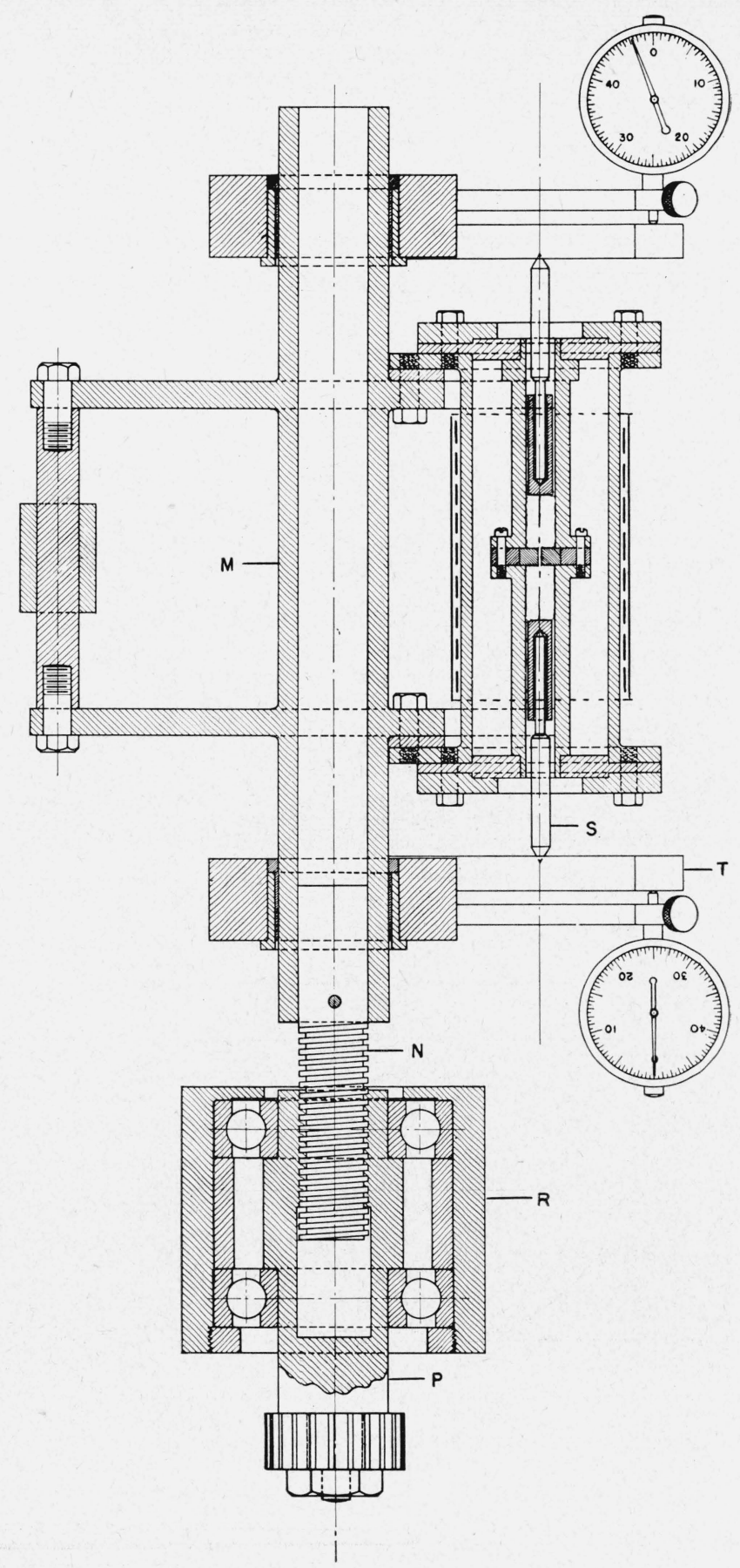

FiguRE 5. Cross section of screw-operated worker-consistometer. 


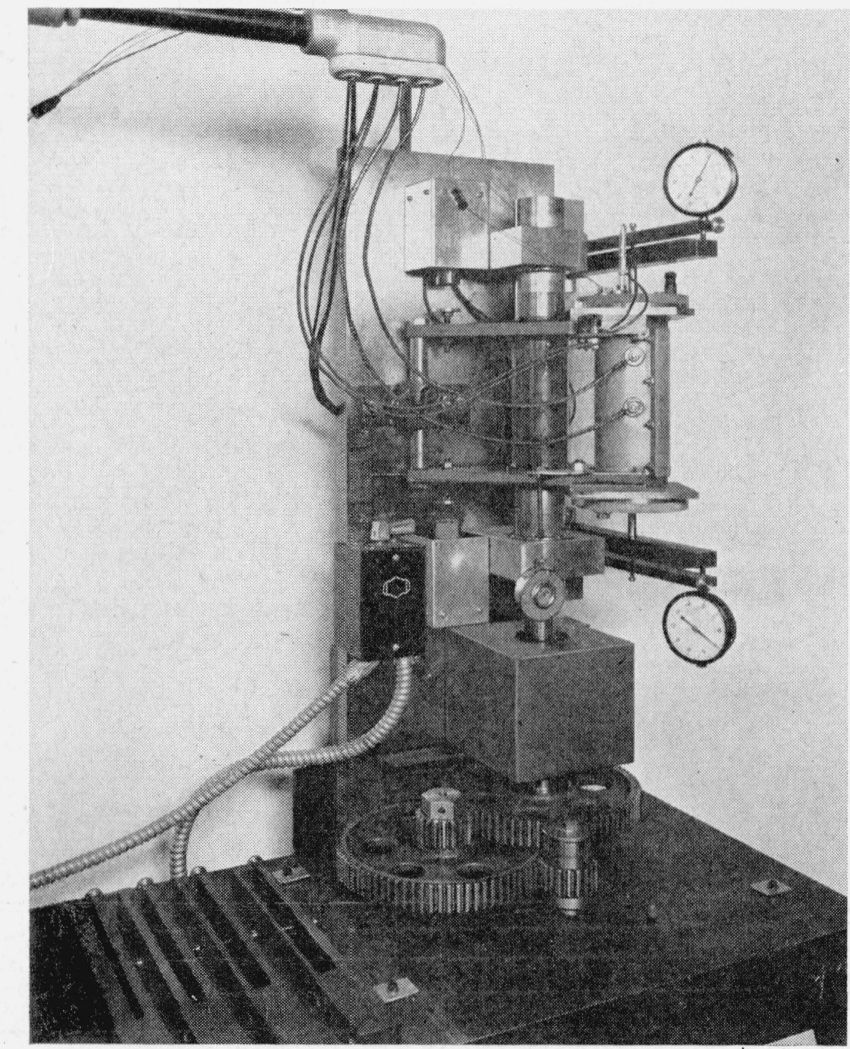

Figure 6. Front view of screw-operated worker-consistometer.

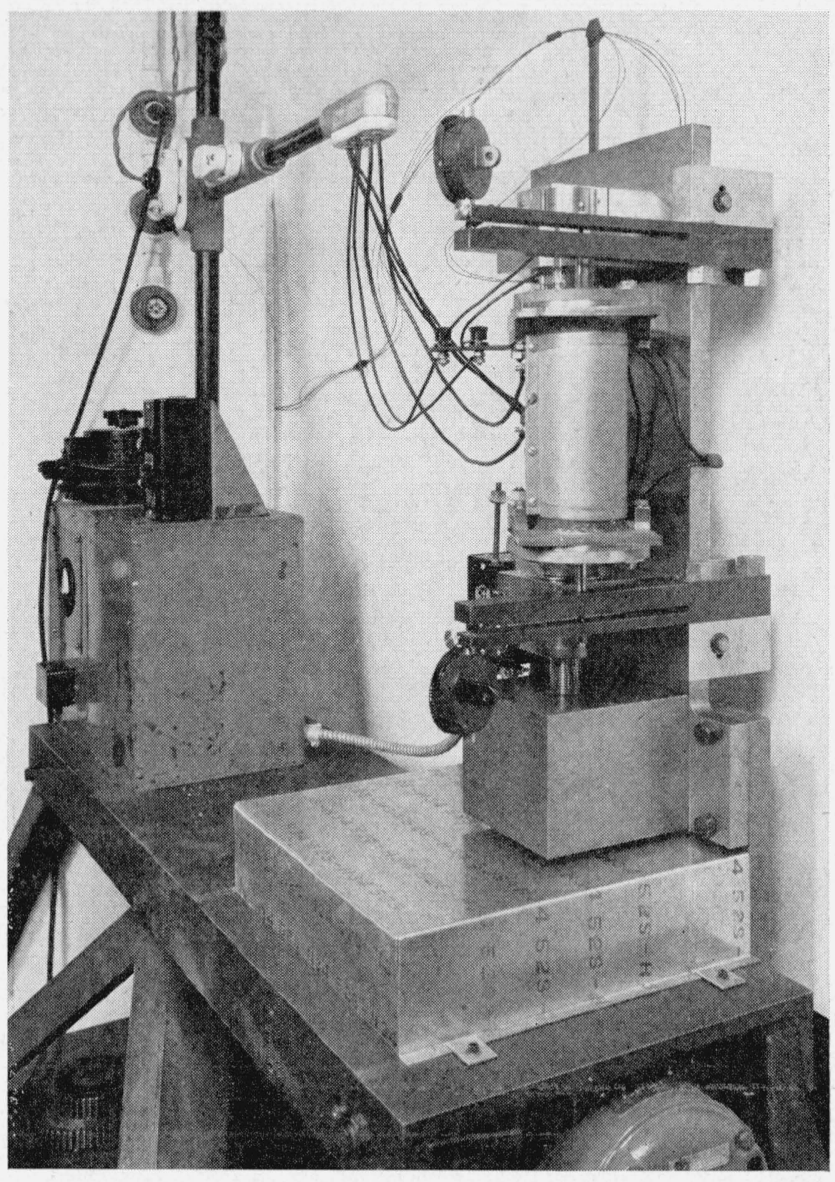

FigurE 7. Side view of screw-operated worker-consistometer.

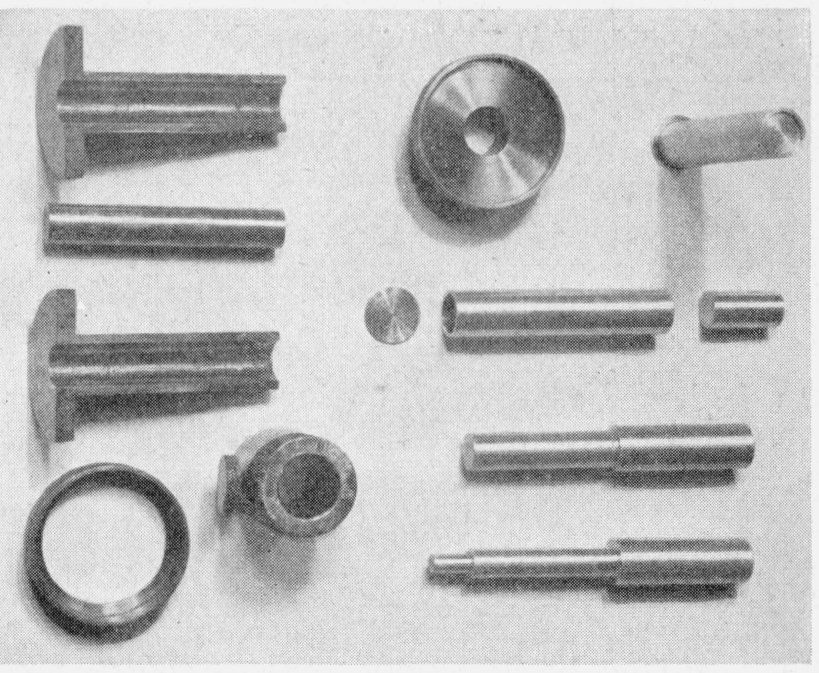

Figure 8. Views of filling and storage apparatus. 


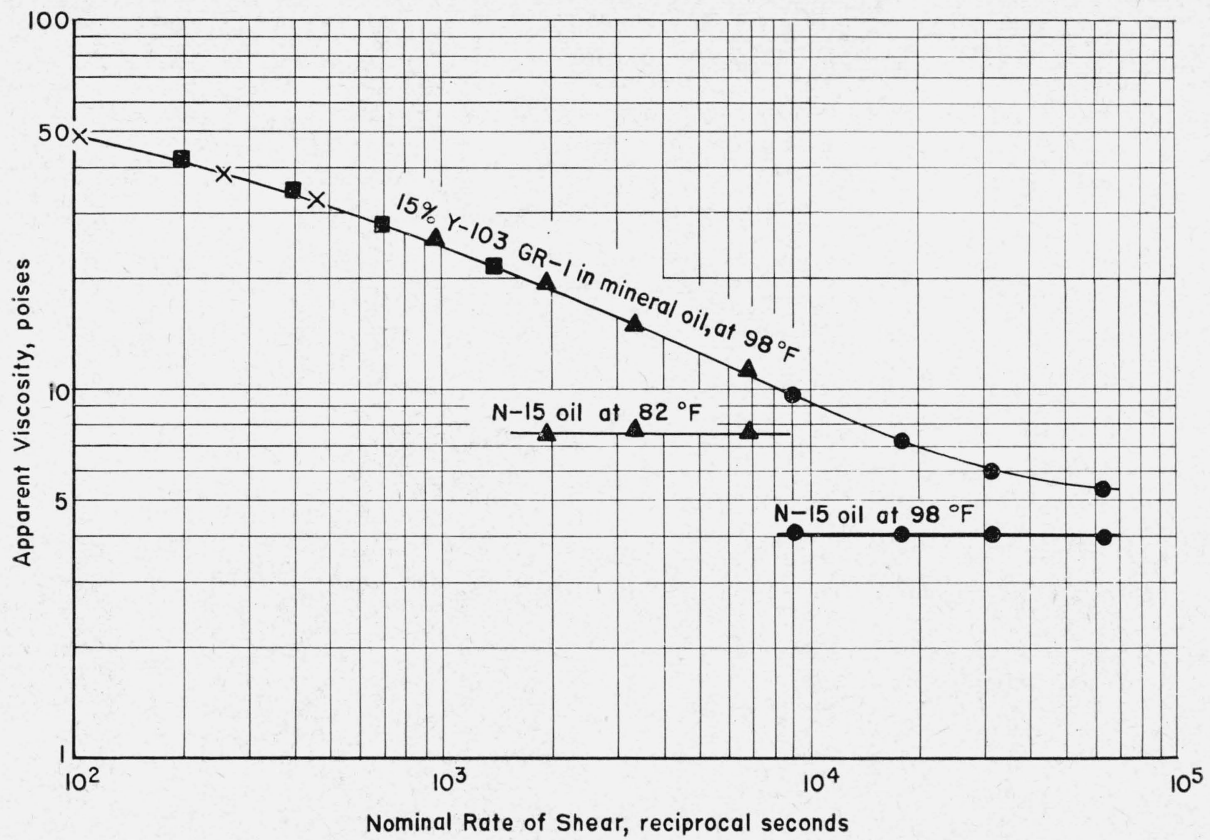

Figure 9. Typical viscosity data at various rates of shear for a Newtonian and a non-Newtonian fluid. - 1-hole disk; $\mathbf{\Delta}, 10$-hole disk; , 50-hole disk; X, 1-hole disk with weights.

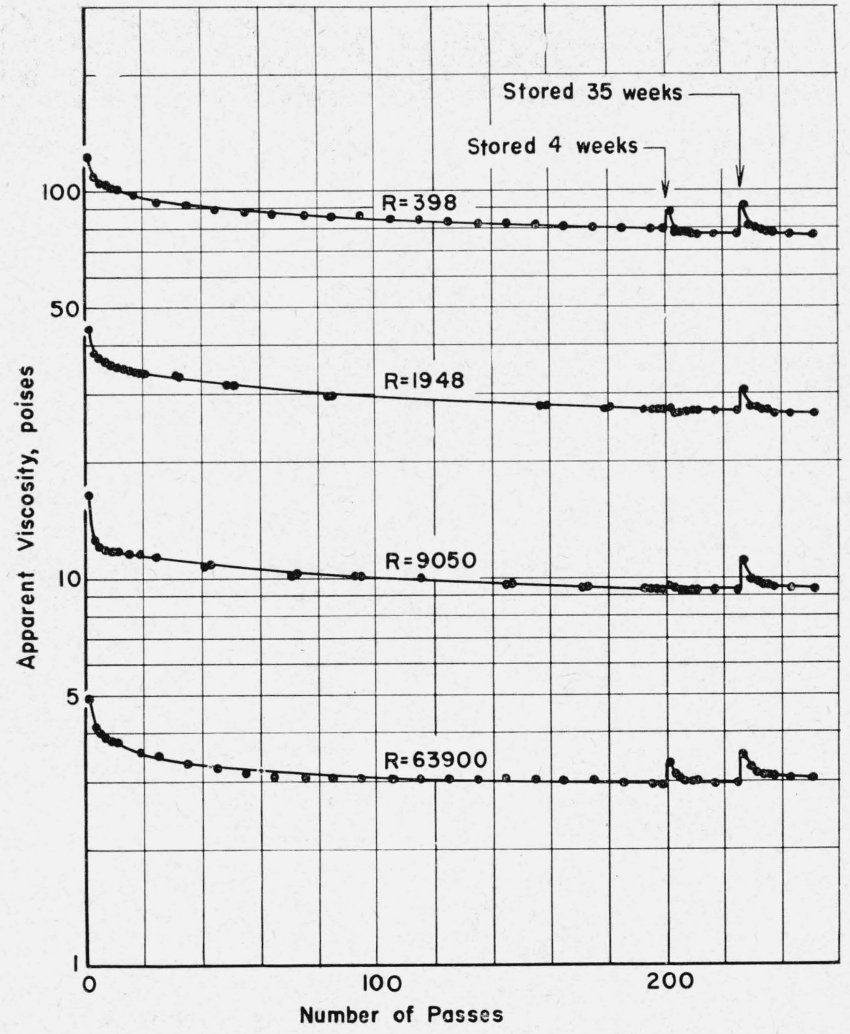

Figure 10. Apparent viscosity of grease $A$ at $100^{\circ} \mathrm{F}$ as influenced by working and subsequent storage.

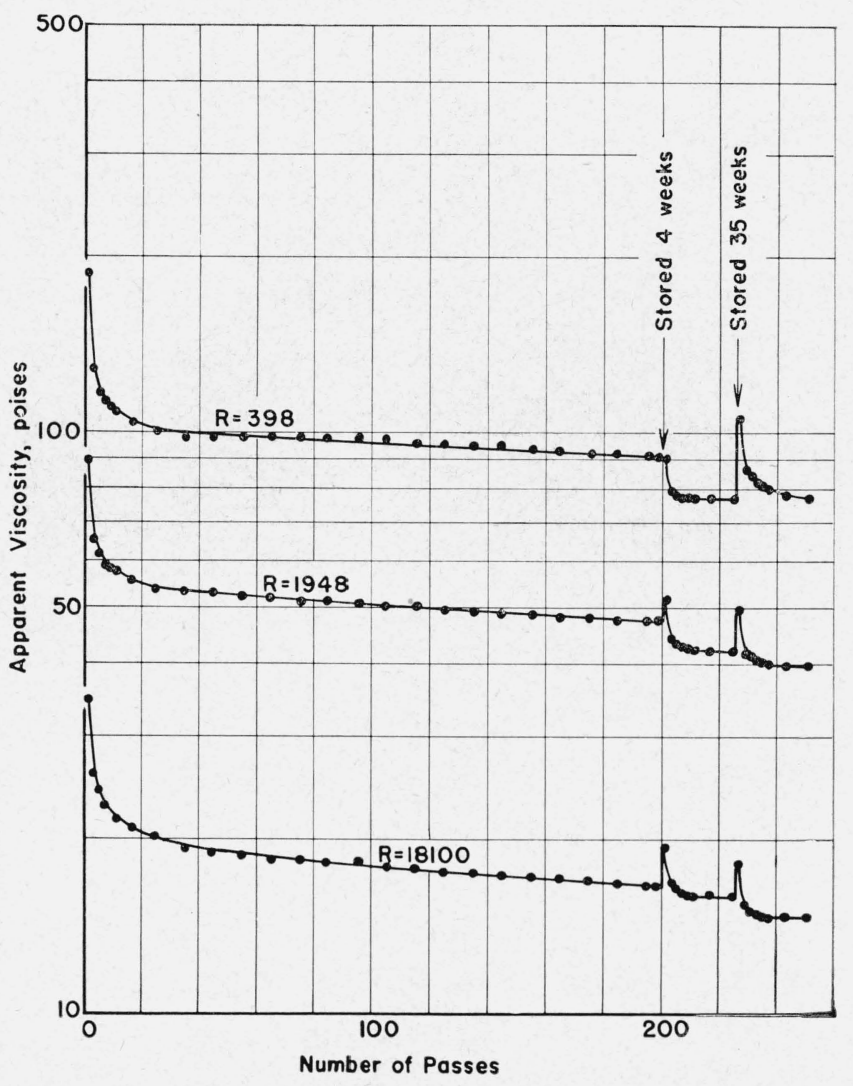

Figure 11. Apparent viscosity of grease $D$ at $100^{\circ} \mathrm{F}$ as influenced by working and subsequent storage. 


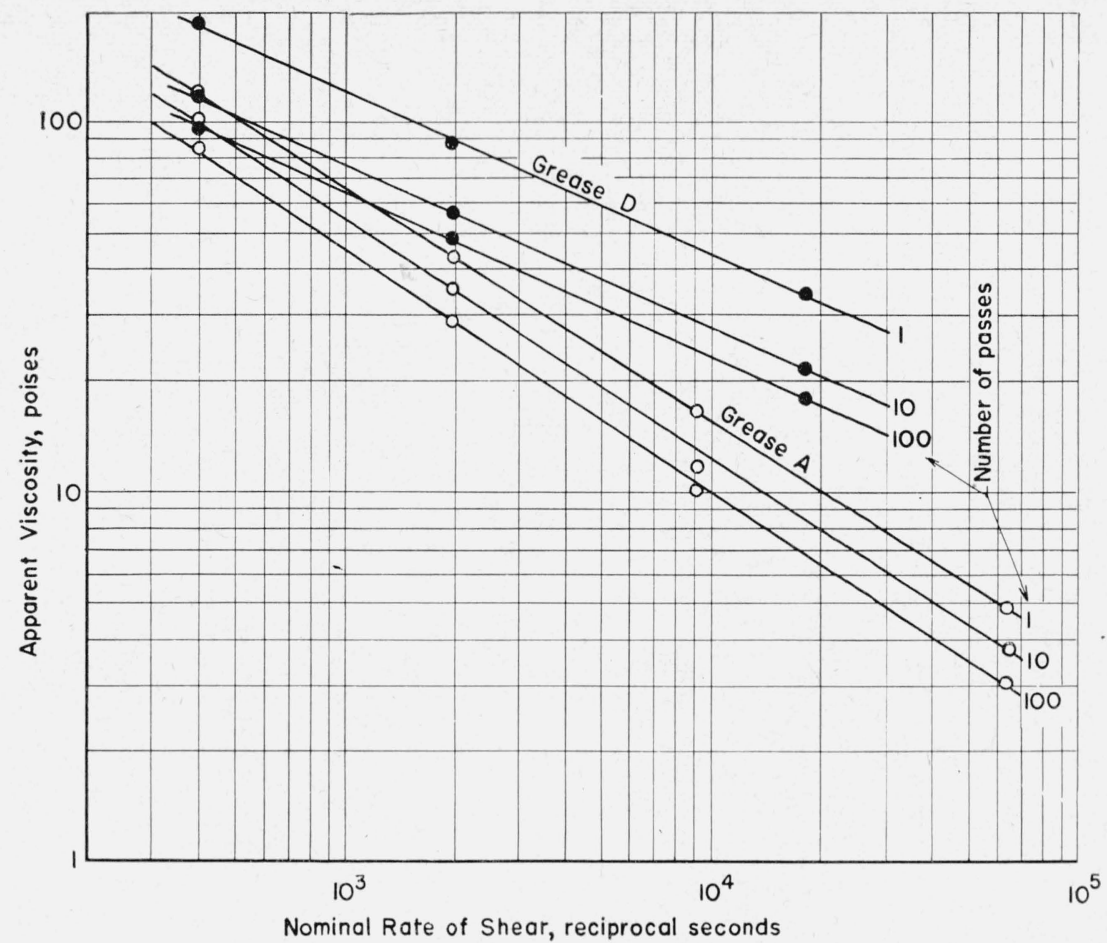

FiguRE 12. Relationship between apparent viscosity at $100^{\circ} \mathrm{F}$ and nominal rate of shear for greases $A$ and $D$ at various degrees of working.

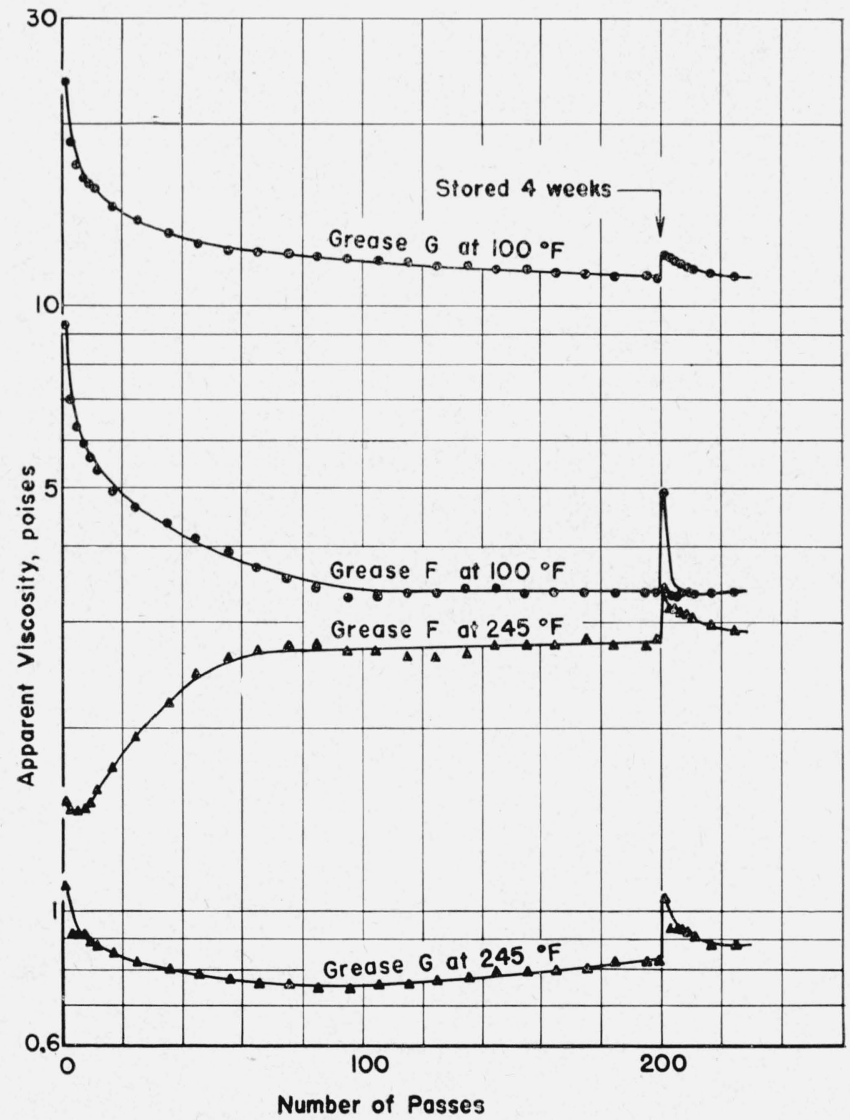

Figure 13. Effect of working and storage on the apparent viscosity of greases $F$ and $G$ at $100^{\circ}$ and $245^{\circ} \mathrm{F}$, at a rate of shear of 18,100 reciprocal seconds. 

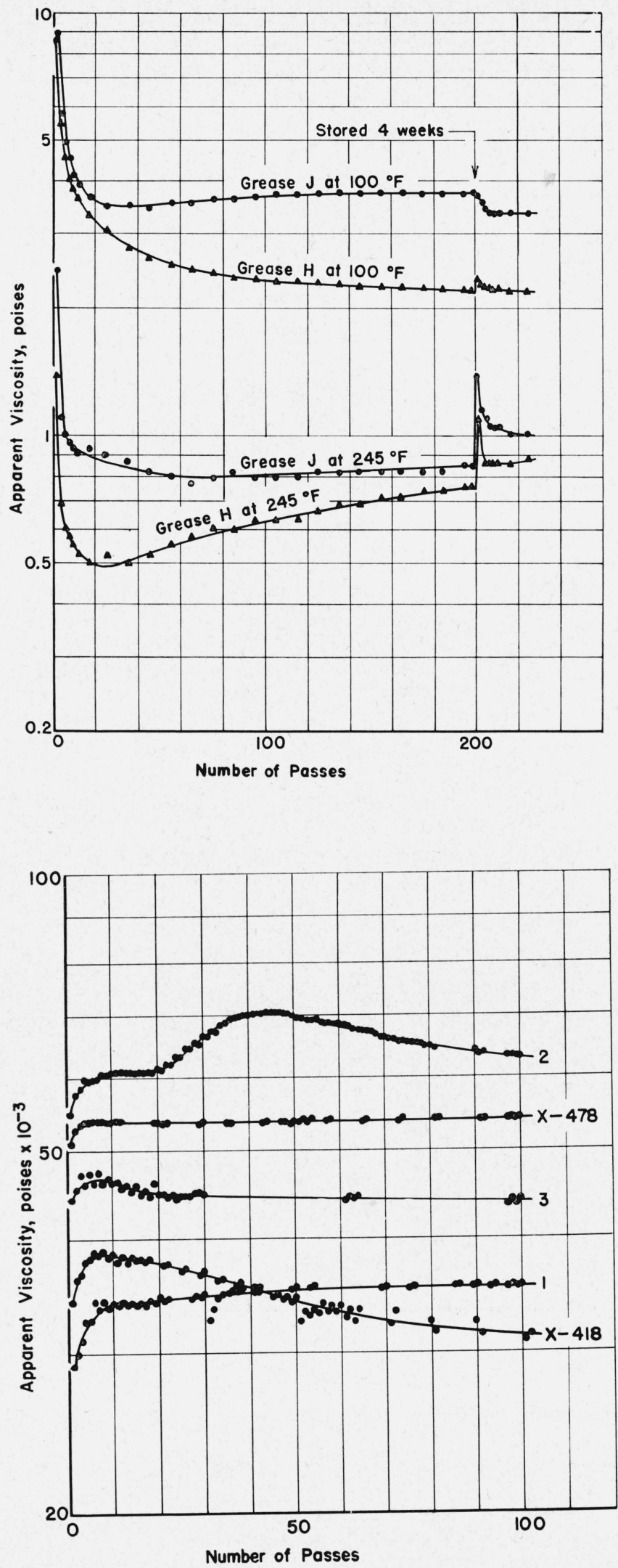

FIGURE 14. Effect of working and storage on the apparent viscosity of greases $H$ and $J$ at $100^{\circ}$ and $245^{\circ} \mathrm{F}$, at a rate of shear of 18,100 reciprocal seconds.
FiguRE 15. Effect of working on the apparent viscosity of five synthetic rubbers at $212^{\circ} \mathrm{F}$, at a rate of shear of 99 reciprocal seconds. 


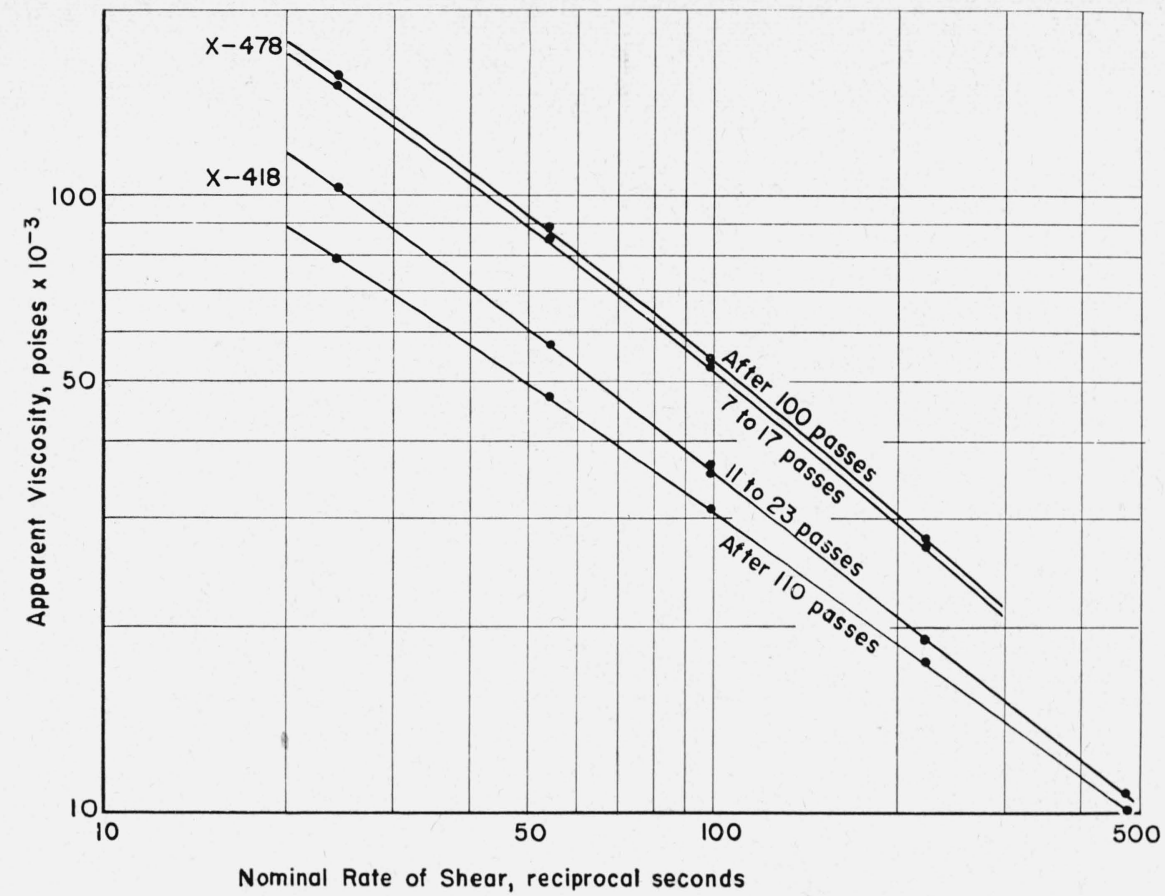

FIGURE 16. Relationship between apparent viscosity at $212^{\circ} \mathrm{F}$ and nominal rate of shear for two synthetic rubbers for various degrees of working.

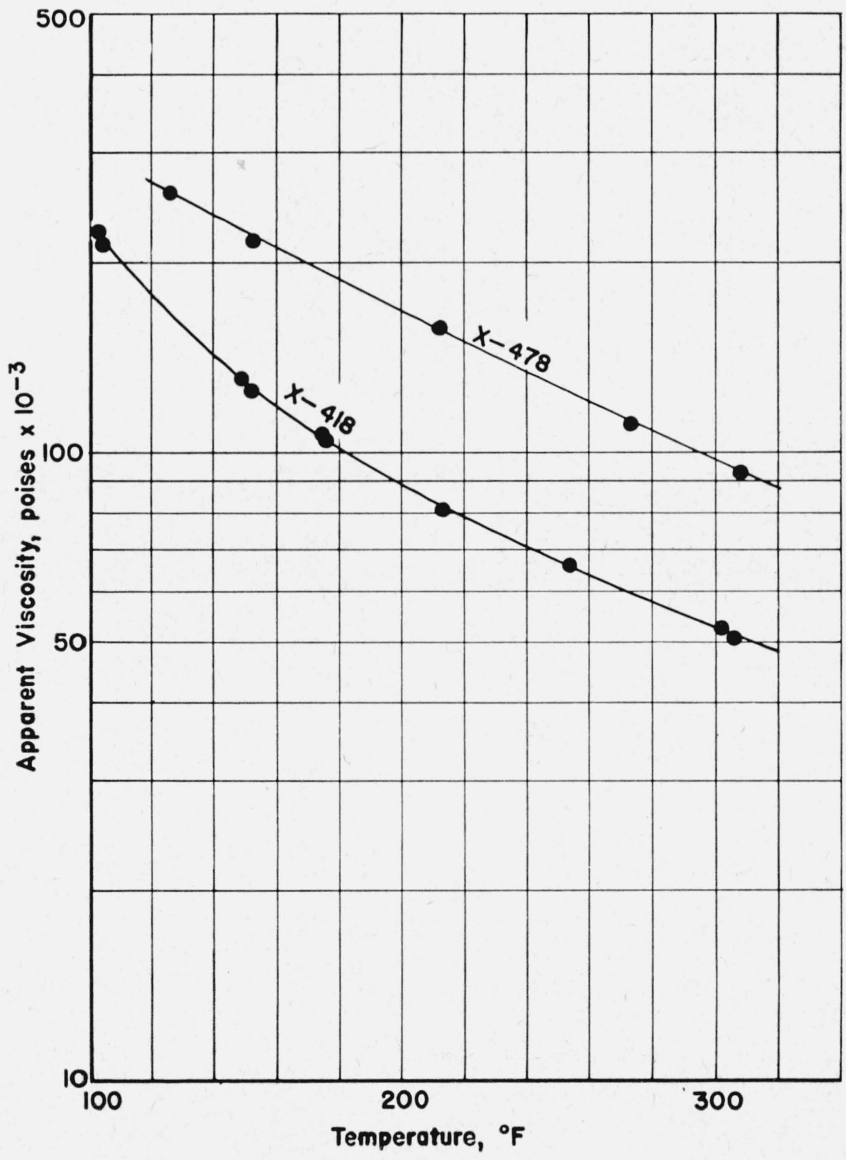

FiguRE 17. Relationship between viscosity and temperature for two synthetic rubbers, at a rate of shear of 24.3 reciprocal seconds. 